\title{
A CULTURA RELIGIOSA NEGRA NO RIO GRANDE DO SUL
}

THE BLACK RELIGIOUS CULTURE IN RIO GRANDE DO SUL

\section{Adalberto Ojuobá Pernambuco ${ }^{1}$}

Foi com imensa surpresa que recebemos o convite formulado pela Fundação Palmares para que participássemos do presente Fórum e isto porque apenas somos estudiosos das Religiōes Afro-Brasileiras, sem títulos acadêmicos e tão somete imbuídos de um acendrado amor pelas mesmas que abraçamos há mais de 40 anos.

Agradecemos ao nosso querido amigo Dr. Ari Pedro Oro a lembrança de nosso nome, fruto talvez da amizade que se construiu quando de suas pesquisas, como antropólogo, em Porto Alegre, quando nos honrou distinguindo-nos com a qualidade de fonte de consultas.

De comum acordo com nossa irmá Rita Segatto que postulou a presença de uma conferencista sobre o Batuque do Rio Grande do Sul, aqui nos encontramos para abordar o assunto ainda hoje quase desconhecido pelo resto do Brasil e que nos parece bastante curioso, em especial para os que se dedicam ao estudo das Religióes Africanas no Brasil, por isso diferente de todas as demais praticadas nos vários estados da Federação, e isto se confirma ao se constatar que o Candomblé tradicional apenas penetrou no nosso Estado há menos de dez anos e raras são as Casas que o praticam. A grande maioria, perto dos $98 \%$, executam o que se denomina de Naçáo, ou um termo usado por estudioso, já não bem-aceito: Batuque.

Um dos fatores que muito contribuiu para o desconhecimento quase total das Religióes Afro-Brasileiras no Rio Grande do Sul foi a ausência de pesquisadores do porte dos que se dedicaram e ainda hoje se dedicam ao Candomblé tradicional e que se detiveram ao estudo daquilo que denominaram

1 Breve biografia do autor presente na abertura deste debate, na apresentação de Carvalho, Veras e Emil. 
de jeje-nagô, ou seja, o ramo ioruba e o ramo daomeano e, a posteriori, o ramo bantu, que se desenvolveu com maior intensidade no Rio de Janeiro, de conformidade com as cargas dos navios negreiros e dos portos onde descarregavam os escravos.

E é neste ponto que nasce a grande disparidade entre o Candomblé e a Nação do Rio Grande do Sul: o fato de que não aportaram no Rio Grande do Sul navios oriundos diretamente da África e que os negros ali chegados vieram dos demais Estados integrando entradas e bandeiras, que deram ao Brasil outros contornos que não o do Tratado de Tordesilhas, pela colonização deste território conquistado palmo a palmo aos espanhóis.

Eram negros das mais variadas etnias e já esposando uma religião que se não chegou pura nos estados mais bem supridos, a nós chegou ainda mais impura e mais cheia de misturas. A isso se soma outra parte de negros que ingressaram no Rio Grande pelas fronteiras do Uruguai e da Argentina e cuja verdadeira identidade tribal nos é inteiramente desconhecida.

Faltaram-nos pesquisadores da competência dos que estudaram a Religiáo nos estados de maior aporte de escravos e da qualidade de um Nina Rodrigues, Arthur Ramos, Manuel Querino, Roger Bastide, Melville J. Herskovits e tantos outros que se dedicaram ao estudo acurado das Religióes e suas origens étnicas.

Tivemos, é verdade, alguns elementos como Dante de Laytano, Carlos Galvão Krebs, Leopoldo Betiol, Edvino Friederichs e Enerso La Porta que foram os pioneiros dos estudos sobre as Religióes Afro-Brasileiras no Rio Grande do Sul e hoje encontramos estudos produzidos por Norton Figueiredo Corrêa e por Ari Pedro Oro e seus alunos, abordando as mais variadas Naçóes cultuadas no Rio Grande do Sul.

Cabe aqui, sem o sentido de crítica, mas táo somente de esclarecimento, uma análise sobre os pesquisadores citados a fim de que possamos entender a extensão da contribuição que trouxeram para os pesquisadores de agora. O pioneiro dos estudos, sem sombra de dúvidas foi Leopoldo Betiol, um autodidata que assumiu, desde logo, uma posição clara na preocupaçáo maior em refutar a pecha de religiáo de ignorantes de que desfrutavam o 
Africanismo e a Umbanda, esta entáo surgindo, e algumas das conclusóes a que chegaram Nina Rodrigues e Arthur Ramos, principalmente no que diz respeito ao caráter psicopatológico do transe. Seus três livros: $O A B C$ da Umbanda, A Umbanda perante a Critica e Do Batuque e das Origens da Umbanda acham-se esgotados desde há muito e trazem subsídios bastante interessantes quando bem analisados.

Depois dele vieram os estudos de Dante de Laytano, professor da Universidade Federal do Rio Grande do Sul e pesquisador incansável do nosso folclore. Católico praticante, suas análises refletem as restriçóes da Igreja Católica contra as religiôes negras. Nada obstante, o seu trabalho encerra muito em contribuiçáo para um estudo posterior e uma visáo bastante interessante das Casas de antanho. Escreveu Festa de Nossa Senhora dos Navegantes (sincretizada com Yemanjá no Rio Grande do Sul), O Negro do Rio Grande do Sul, A Igreja e os Orixás e os Africanismos do Dialeto Gaúcho.

Tivemos a ventura da amizade do Dante e de visitarmos a sua casa na Avenida Carlos Gomes, em Porto Alegre, onde mantinha uma expressiva biblioteca. Já avançado em idade e tendo enviuvado, viu-se na contingência de se mudar para a zona central de Porto Alegre, para um apartamento na rua Duque de Caxias que não comportava o grande número de volumes que possuía, obrigando-o a se desfazer da grande maioria. Sabedores de que pretendia publicar um novo volume enfatizando suas visitas às Casas de Naçáa ${ }^{2}$ antigas, mas que seu estado de saúde não lhe permitiria mais fazê-lo, tomamos a liberdade de procura-lo e solicitar-lhe a doação de seus cadernos de apontamentos, em número de 30, para que pudéssemos tentar a compilaçáo do livro. Para nossa surpresa e desgosto, informou-nos que eles haviam sido destruídos juntamente com o material que não mais pretendia utilizar, por absoluta falta de espaço. Perdeu-se assim um precioso acervo sobre as Religiōes Afro-Brasileiras no Rio Grande do Sul.

2 Casa de Nação era uma das formas de denominação dos terreiros de Batuque (ou Nação) no Rio Grande do Sul. 
Edvino Friederichs, padre jesuíta, escreveu um livro intitulado Onde os Espiritos Baixam, com o sugestivo subtítulo "Orientação para os católicos sobre Espiritismo, Umbanda e charlatanismo" em que vários capítulos dizem respeito às Religiôes Afro-Brasileiras tais como: "Uma Noitada de Batuque Jeje-Nagô" e onde, inclusive, descreve uma cerimônia completa do sacrifício de animais e de um ritual de Batuque em uma linguagem eivada dos preconceitos já evidenciados por parte da religiáo de que era sacerdote, mas, ainda assim, interessantes no seu conteúdo.

Carlos Galvão Krebs talvez tenha sido o elemento que mais documentou as cerimônias, constituindo um valioso arquivo e que, com seu desencarne, permanece em poder de seus herdeiros que buscam um comprador. Face às dificuldades de colocá-lo junto ao Governo do Estado, acreditamos que tal acervo seja adquirido por outro Estado da Federaçáo. Cabe-nos consignar que, afora alguns artigos publicados em jornais, o único livro que escreveu sobre as Religiôes Afro-Brasileiras, Estudos de Batuque, está muito aquém de todo o material que possuía e que lhe teria permitido escrever um livro substancioso sobre tudo o que tivera a oportunidade de assistir.

Mais feliz do que ele foi o seu acompanhante, o psiquiatra Ernesto La Porta que analisou o nosso Batuque à luz da psiquiatria escrevendo um livro, com o mesmo título e que, conquanto parcial, se considerada a formação freudiana do autor, encerra valiosos subsídios aos que se dedicam ao estudo da Religiáo.

Dos contemporâneos, Norton Correa transformou em livro a sua tese de Mestrado pela UFRGS, em que apresenta um estudo de campo realizado em sua maior parte em duas grandes Casas de Porto Alegre. É um livro interessante, sob todos os pontos de vista, abordando as Religióes sob um ângulo diferente e, se falhas tem, e as tem, decorrem estas do fato de se dizer náo iniciado e, portanto, basear suas assertivas apenas em declaraçôes de informantes entre os quais alguns não possuidores dos fundamentos que alegavam ter e, outros, capciosos em suas informaçóes, por desconhecerem a finalidade da pesquisa e a julgarem dirigida para obter conhecimentos que lhe permitissem abrir uma casa de religiāo. É, no entanto, portador de 
um considerável acervo de slides e fotos, a maior parte dos quais tirados na Sociedade Africana Nossa Senhora dos Navegantes, da Yalorixá Ester da Yemanjá, já desencarnada, e cuja execução teve que ser autorizada pelo próprio Orixá, em nossa presença, tendo em vista a finalidade a que se destinavam e a manifesta resistência dos filhos-de-santo da Casa, contrários à documentação fotográfica.

Resta-nos Ari Pedro Oro, doutor em Antropologia e professor da Universidade Federal do Rio Grande do Sul, hoje a nosso ver, a maior autoridade no assunto. Seu trabalho prima pela seriedade e seus artigos vêm sendo publicados pela editora da própria Universidade a par dos realizados por seus colegas Alejandro Frigerio, da Argentina, e Renzo Pi Hugarti, do Uruguai, o que os tornou conhecidos como os pesquisadores do Mercosul. Entre os vários artigos escritos por Ari Pedro Oro podemos destacar As Religiöes Afro-Brasileiras: Religióes de Exportação, Difusão das Religióes Afro-Brasileiras Para os Países do Prata e a conferência que pronunciou no II Seminário Cultural e Teológico da Umbanda e das Religióes Afro-Brasileiras intitulada A Participação dos Descendentes Alemães e Italianos na Umbanda e nas Naçóes Africanas do Rio Grande do Sul. Seria, indubitavelmente, o maior estudioso das Religióes Africanas no Rio Grande se conseguisse reunir reminiscências, o que julgamos difícil. É, contudo, o mais profundo conhecedor da atualidade religiosa e um mestre que incentiva seus discípulos a darem continuidade aos seus estudos.

Visitaram, também, o Rio Grande do Sul dois pesquisadores: Melville J. Herskovits e Roger Bastide produzindo artigos sobre o que presenciaram em Porto Alegre em suas curtas permanências. De Herskovits tivemos $O$ Extremo Sul dos Africanismos do Novo Mundo e Os "Parás" de Porto Alegre, e de Bastide O Batuque de Porto Alegre e O Batuque do Rio Grande do Sul, constantes de suas obras Sociologia do Folclore Brasileiro e Religióes Africanas no Brasil. Mesmo considerando o pouco tempo que aqui permaneceram pode-se constatar, desde logo, a visível preocupação de ambos em fazer uma comparação entre a religião aqui praticada e a da Bahia, por eles considerada como a religião verdadeira. 
Mas voltemos ao que afirmamos no início do presente trabalho, ou seja, os escravos aportados no Rio Grande do Sul não vieram diretamente da África, conquanto alguns deles fossem africanos legítimos. Vieram de outros estados quer em expediçôes, quer importados diretamente pelos donos de charqueadas a principal fonte de riqueza daquela época. Trouxeram, como é natural, a sua religiosidade, mas já bastante deturpada e, inclusive, mesclada pela fusão de etnias a que havia sido submetida nos estados de origem.

Baseamos a nossa assertiva em consultas aos mais variados historiadores que compulsaram a vinda dos negros e sua contribuição ao desenvolvimento do Rio Grande do Sul, tais como: Cláudio Moreira Bento, João Machado Ferraz, Dante de Laytano, Mário José Maestri Filho e Verônica A. Monti. Todos eles dáo como ponto de referência do afluxo de escravos para Rio Grande do Sul o nosso porto de Rio Grande, pelo sul do estado, e o porto de Laguna em Santa Catarina, de onde se deslocaram, por via terrestre, para cá.

Do Rio Grande migraram para Pelotas, cidade vizinha, para o centro de charqueadas onde era utilizada sua mão-de-obra. Aliás, sobre este assunto seria conveniente reportarmo-nos a dois autores: Arsène Issabelle e Auguste de Saint-Hilaire, seus livros que, por coincidência, denominamos Viagem ao Rio Grande do Sul. Cabe advertência, eis que os livros em questáo foram responsáveis para o fato de que dois notáveis escritores gaúchos comprometidos com o chamado Movimento Tradicionalista Gaúcho, Walter Spalding e Moysés Vellinho, defenderam a chamada "democracia racial" no Rio Grande do Sul, dizendo náo existir maus tratos para com os escravos, sem atentarem para o fato de que os dois visitantes aludiram apenas ao tratamento diferenciado dado pelos pecuaristas aos seus escravos, o que na realidade náo existia com referência aos escravos localizados nas charqueadas, estes de vida curta como os trabalhadores das salinas e até mesmo aos que eram utilizados nas cidades maiores na qualidade de domésticos.

Ainda sobre o assunto, mas já sobre outro ângulo, outro notável historiador, Manoelito de Ornellas, procura justificar a pretensa democracia racial com o argumento de que isto se devia ao fato de que jamais havia sido elevado o número de negros, arrolando pesquisa de Spalding realizada 
entre 1816 e 1829 e que indicava a presença de apenas 26.600 escravos. Esqueceu-se, contudo, que esse número representava o percentual de $30 \%$ do total de habitantes do Rio Grande do Sul.

Foi este, a nosso ver, o fator principal de sua diferenciação no que diz respeito às outras cultuadas nos demais estados da Federação e, principalmente, a variada quantidade de Naçóes reverenciadas pelos gaúchos e inexistentes, até, em outros locais do país. Senão vejamos: atualmente encontraremos Casas ${ }^{3}$ que dizem trabalhar no ritual das seguintes Nações: Jeje, Ijexá, Oyó, Cabinda e Nagó. Analisemo-las e verificaremos, com surpresa, que na realidade os rituais se consubstanciam em apenas um, o Ijexá, e este já bastante afastado do existente em outros estados que utilizam a denominação de Candomblé.

JEJE - Está praticamente extinto dentro do Rio Grande do Sul. Trazido pelos antigos escravos a sua maior diferença dizia respeito à ordem das rezas e ao uso de aguidavis ${ }^{4}$ para tocar os atabaques. Certamente a qualidade das rezas muito mais ligeiras do que as do Ijexá, obrigou os tamboreiros a os colocarem entre as pernas e as dificuldades maiores do toque com varetas para o toque com as mãos, tornou praticamente inexistente a categoria de tocadores de Jeje e apenas algumas Casas ainda mantêm uma ou outra reza em homenagem aos Babalorixás, ou Yalorixás das suas Casas Mães. Estas Casas se denominam Jeje-Ijexá, a nosso ver erroneamente, eles que cultuam apenas Orixás e as rezas são, em sua grande maioria, de procedência ioruabana. Hoje resta-nos o Babalorixá Pirica do Xangô, último Alabé que ainda utiliza aguidavis e que se locomove em uma cadeira de rodas pela perda de suas duas pernas em consequência do diabetes. Não deixa um sucessor sequer. IJEXÁ - Predominante dentro das Nações Africanas no Rio Grande do Sul impôs os seus Orixás e a ordem das rezas que lhe são oferecidas,

3 Quando o autor se refere a "casas", ele se refere aos terreiros ou às casas onde acontecem o Batuque, que no caso do Rio Grande do Sul, dividem o espaço da casa de habitação dos pais e mães de santo.

4 Aguidavis, são as baquetas para tocar os tambores na nação Jeje, que desde o período da escrita do texto já pouco se via. 
sem sombra de dúvida. Assim teremos, pela ordem: Bará, Ogum, Yansã, Xangô, Obá, Odé, Otim, Ossanyn, Xapanã, Oxum, Yemanjá e Oxalá, os doze Orixás cultuados no nosso estado.

OYÓ - Poucas são as Casas que ainda se dizem de Oyó e cuja principal distinção das demais está apenas nas tiradas das rezas que obedecem a seguinte ordem: Bará, Ogum, Xapanã, Odé, Ossanyn, Yemanjá, Obá, Otim, Oxum, Oxalá, Yansã e Xangô. Como se vê, primeiro são invocados os Orixás masculinos e logo após os femininos, ficando para o final o Oxalá, andrógino, Yansã e Xangô por serem considerados a rainha e o rei de Oyó. Outro ponto fundamental é a chamada "Obrigação das Cabeças", onde os Orixás dançam trazendo à boca as cabeças dos animais para eles sacrificados e já em adiantado estado de putrefaçáo a fim de provarem a possessão completa dos seus filhos.

CABINDA - Ainda existem muitas Casas que cultuam esta Naçáo de origem daomeana. No entanto, fazem-no reverenciando os Orixás iorubanos e não os inkices, como seria de direito. Apenas antes do Bará são entoadas as rezas para o Legbara, último resquício dos que antigamente foram cultuados. Sobre uma destas casas deteremos nossa atenção no correr da conferência.

NAGÔ - Em extinção quase total. Não resta, em Porto Alegre, senão uma Casa que pratica este culto e sobre a qual falaremos no correr de nossa palestra, por algumas peculiaridades que nos afiguram importante ressaltar.

Infelizmente, os fundamentos ${ }^{5}$ que nos foram legados, náo permitem a fotografia ou filmagem de médiuns em possessão e, destarte, raras são as Casas que permitem a presença de pessoas portando máquinas da espécie. Dentre elas, encontra-se o Reino de Oxalá, do Babalorixá Cleon do Oxalá.

A Casa do Cleon diz praticar a Cabinda, mas não venera os inkices de Angola e do Congo ou, até mesmo, os Voduns daomeanos. Reverencia, isto sim, os Orixás iorubanos, para eles toca e a eles saúda em seus rituais.

5 Esta é a forma como os afrorreligiosos no Rio Grande do Sul se referem ao conjunto de ensinamentos que é passado de geração em geração sobre as formas dos ritos, e que lhes garantem o vínculo ancestral.

Debates do NER, Porto Alegre, ano i9, N. 35, P. 2 I-38, JAN./Jul. 20 I 9 
Apenas, como já o dissemos, inicia o toque invocando o Legbara, entidade Jeje que só o ritual de Cabinda evoca.

Assim, verifica-se a utilização do ritual ijexá em quase todo o Rio Grande do Sul, manifestando-se, contudo, de forma bastante divergente do mesmo ritual utilizado nos chamados candomblés tradicionais e, portanto, diferenças essenciais que passaremos a comentar.

Ainda que o Chirế ${ }^{6}$ do Candomblé e a Gira da Nação sejam, em essência, idênticos, apresentam uma diferença fundamental que se constitui no fato de que os Orixás, nos Toques de Nação, não são recolhidos ao Roncó para serem paramentados ${ }^{7}$ e isto porque os seus aparelhos já ingressam na gira portando uniformes em que se ressaltam as suas cores, na maior parte das vezes. Assim sendo, na medida em que váo chegando, colocam-se na parte central da gira, que continua o seu trajeto independentemente da vinda dos Orixás, permanecendo estes no próprio recinto em que se realiza a homenagem.

Os Orixás da Nação, como já o dissemos, náo envergam os paramentos típicos de cada Orixá usados no Candomblé, limitando os filhos de cada Orixá a utilizarem os trajes tradicionais, que se constituíam em blusa e saia para as mulheres e blusa e bombachas, ou calças, para os homens. Dizemos constituíam, pois, hoje, com a para nós famigerada modernização, os trajes revestem-se de uma luxuosidade jamais admitida na antiguidade, quando as mulheres usavam a chita e os homens o algodáo em seus axós 8 . Sedas, veludos, lamês, bordados, paetês, bombachas, que se confundem com saias tal a largura

6 O autor refere-se ao Sirè, a roda ou festa aos Orixás.

7 No Candomblé, quando o Orixá se manifesta é levado ao Roncó (quarto de santo) para que seja vestido com as roupas característicos do Orixá. No caso do Batuque, quando narra o autor isso não ocorre, porque as vestimentas (paramentas) das pessoas já fazem alusão (pela cor) de seu Orixá.

8 Como são denominadas as roupas para a festa no Batuque. 
que apresentam, e joias são enxertos de um presente que, nos parece, visa descaracterizar a Religião ${ }^{9}$ ao destruir a ancestralidade que lhe é inerente.

Outro ponto a ser observado é que os Orixás se dirigem verbalmente aos fiéis e, ainda que não tenham a verbosidade de um caboclo ou um pretovelho de Umbanda, dão conselhos e consolam aos que buscam procurando um axé. Esta foi uma das mais controversas dúvidas que nos assaltou até lermos o livro Um Vento Sagrado da autoria de nossos irmãos Muniz Sodré e Luís Filipe de Lima, e versando sobre a vida de Agenor Miranda Rocha, um dos últimos, senão o último Oluô vivo, onde constatamos que os Orixás dos antigos, no Ketu, "sempre falavam, ou em iorubá, ou para aqueles que não compreendessem esta língua, num português meio arrevesado”. Aliás, muito do que se contêm naquelas entrevistas se casa com o que vimos no atual Culto Africano praticado no nosso Rio Grande do Sul, quer com referência à fala dos Orixás, quer quanto ao luxo exagerado que vem Imperando nos Toques.

Vários são os cerimoniais que se realizam dentro de nossos Toques de Nação e que não são realizados nos Candomblés, tidas como: o Peixe, a Mesa de Ibejis, a Mesa dos Prontos, a Balança, o Despacho do Ecó e a Dança do Atã ${ }^{10}$.

Iniciemos pela chamada Festa do Peixe que se efetiva, de modo geral, na quarta-feira seguinte à festa (normalmente ocorrida num sábado), e que se constitui em uma matança de peixes vivos e um toque levado a efeito na noite do mesmo dia. A variação principal é que se trata de uma homenagem aos Orixás Funfun e, portanto, exige-se o uso exclusivo do traje branco. Segundo pudemos constatar em nossas pesquisas, esta festa é uma reminiscência do período de escravidão e tem profunda ligação com o ciclo Peixes

9 Outra forma pela qual as pessoas comumente denominas o Batuque ou Nação.

${ }^{10}$ Aqui o autor se refere a momentos específicos da festa, ou do toque (que compreende todos os dias de recolhimento de quem passa pela feitura), que não são vistos no Candomblé. 
da Igreja Católica Apostólica Romana, eis que durante a cerimônia não se sacrifica e nem se ingere animal de carne vermelha.

Outra que se vem tornando cada vez mais rara é a chamada Mesa dos Prontos, tradicionalmente executada, também, na chamada Festa Grande, pelas Casas de porte e fundamento, que está se extinguindo rapidamente. Após as rezas de Oiá, estende-se uma toalha branca no chão do recinto sagrado e ali colocam-se pratos contendo as comidas prediletas de cada Orixá.

O Babalorixá ou Yalorixá que comanda a Casa senta-se no chão e à cabeceira da mesa, e em volta, obedecida a ordem hierárquica, acomodam-se os filhos de cada Orixá possuidores de todos os axés. A curimba ${ }^{11}$ inicia o toque com rezas de Bará a Oxalá e o dirigente da mesa principia o trânsito dos pratos na mesma ordem, devendo cada um comer pelo menos um pouco de cada obrigaçáo. À passagem do prato de Oxalá, encerra-se o toque, levantando-se ritualisticamente a mesa.

Aliás, já havíamos abordado este assunto em nosso livro Omolokô, Origem e Ritual, editado em 1989 pelo CONDU - Conselho Nacional Deliberativo da Umbanda e dos Cultos Afro-Brasileiros, sob os auspícios da Secretaria da Comunicaçáo Social do Governo do Estado do Rio de Janeiro.

A seguinte é a que denominamos de Balança. Trata-se de um ritual que só é levado a efeito quando da Obrigaçăo de Quatro Pés, ou seja, na oportunidade em que se sacrificam animais de pelo para os Orixás. Nesta ocasião e logo após as rezas para Xangô, interrompe-se o ritual e forma-se uma roda constituída de elementos desincorporados, portadores de todos os axés e, portanto, com todos os Orixás assentados em suas vasilhas. $\mathrm{Na}$ roda se observa a ordem dos Orixás iniciando-se pelos filhos de Bará (Exu) e, finalizando, pelos de Oxalá. Esta roda é constituída de múltiplos de 6 (o axé de Xangô) e, se excede o número de 36, formam-se duas rodas distintas e que se sucedem: uma constituída pelos filhos dos Orixás do Seco e outra pelo da Água (Oxum, Yemanjá e Oxalá).

${ }^{11}$ É como o autor faz referência ao toque do tambor. Atualmente, curimba é um termo mais vinculado aos rituais da Quimbanda. [N.E]

Debates do NER, Porto Alegre, ano i9, N. 35, P. 2 I-38, Jan./Jul. 20 I 9 
Ao início, os participantes entrelaçam as mãos e a curimba principia a reza da Balança que se movimenta na direção periferia/centro, retornando à periferia. A curimba vai acelerando o ritmo do toque até chegar ao auge, quando começam a incorporar os Orixás. Neste ponto muda-se o toque, desfaz-se a roda e a maioria dos Orixás já se encontra no mundo permanecendo no centro da Gira, que reinicia a sua caminhada a ela integrando os não incorporados que participaram da Balança.

Este ritual é encarado com muita seriedade pelas nossas Casas que o consideram como a pesagem da Obrigação. Se não baixarem Orixás na mesma, então algo de errado ocorreu durante a matança e os Orixás se recusam a aceitar o Toque em seu louvor. Há um cuidado todo especial para que se não quebre a corrente constituída na Balança, pois isto traria efeitos desastrosos para o dirigente da Casa. É de se notar que a Balança significa o equilíbrio da Casa e, portanto, uma igualdade, medidas as proporçóes, entre Órum e Ayé.

Analisando os fatos e levando-se em conta que a Balança é dedicada a Xangô, ou melhor, especificamente ao Xangô Aganju, o encarregado da pesagem das almas que se dirigem ao Órum, podemos constatar que o movimento de ida e volta da roda formada pelos participantes pode ser tranquilamente definido como o movimento das correntes reencarnatórias, em seu fluir e refluir na trilha Órun/Àiyé, ou seja, centro/periferia. É um movimento de caráter perpétuo e náo deve jamais ser interrompido a não ser quando atingiu o seu objetivo e este é caracterizado pela presença dos Orixás.

Daí o porquê de a corrente náo poder ser rompida sob pena dos mais severos reflexos no tocante à Casa, aos seus dirigentes, e em especial, aos causadores da ocorrência. E veja-se que, nesses casos, a primeira providência a ser tomada é cobrirem-se os envolvidos no Alá de Oxalá e suplicar-se àquele Orixá o seu perdáo. Em se tratando de uma cerimônia em que se representa a débil fronteira entre a vida e a morte, apenas Oxalá, o Orixá maior, dispóe de poderes para relevar as falhas.

Ao descrevermos este ritual constatamos mais uma diferença entre a nossa Nação e o Candomblé. No Rio Grande do Sul preparam-se os filhos 
do Bará, que corresponde ao Exu, e este participa de toda a obrigação. Não se usa, pois, o Padé de Exu, figurando a entidade no saláo entre os demais Orixás e no mesmo nível. É um dos fundamentos que podem até ser contestados pelos candomblezistas mas que jamais poderá ser erradicado de nosso meio, tal a força assumida pelo fundamento em questão. Toque onde não esteja presente um Bará incorporado é tido como incompleto, pois a ele cabe abrir os caminhos e conduzir as súplicas a Olorum.

Aliás, no tocante ao Padé de Exu é realizado o que chamamos de Despacho do Ecó ${ }^{12}$, uma obrigaçáo levada a efeito entre as rezas de Xapaná e as de Oxum. Consiste em um Ecó para o Bará e que é acompanhado por quartinhas ${ }^{13}$ de variados Orixás e que são colocadas no centro do saláo, de onde entidades incorporadas levantam-nas para despachar a obrigaçáo no cruzeiro $^{14}$ mais próximo. $\mathrm{O}$ conjunto carrega, consigo, toda a carga existente na Casa, inclusive a oriunda dos assistentes. Isto nos leva ao fundamento de que náo deva ser olhada pelos presentes sob pena de o curioso atrair para si toda ou parte da carga negativa ali existente. Observa-se, pois, que, longe de se constituir de uma oferenda visando agradar o Exu, é uma limpeza feita e entregue ao Bará para que a conduza ao seu destino.

A Dança do Atã é uma das mais curiosas da nossa Nação. Trata-se de uma encenação que procura lembrar a fuga de Yansã da companhia de Ogum para a de Xangô. Portando uma garrafa devidamente ornamentada, Oiá vai dançando e oferecendo o líquido para Ogum, enquanto este duela com Xangô, ambos levando suas armas ritualísticas. Finalmente Ogum se deixa vencer pela bebida e Yansã parte acompanhada de Xangô. Representa, a nosso ver, a supremacia da justiça sobre a Demanda.

\footnotetext{
${ }^{12}$ A saída do Ecó é a limpeza do terreiro feito por Xapanã e entregue à Bará.

${ }^{13}$ São vasilhas de barro, que devem sempre ser preenchidas de água.

${ }^{14}$ Cruzeiro ou encruzilhada, geralmente o cruzamento entre duas ruas ou avenidas.
} 
Ao encerramento da Obrigação de Quatro Pés ${ }^{15}$, organiza-se a Mesa de Ibejis, ou seja, antes de se formar a roda dos adultos forma-se uma das crianças de até 12 anos e que gira em torno de uma mesa posta ao cháo e onde as comidas ritualísticas são substituídas por uma canja, frutas e doces das mais variadas espécies. Puxa-se a chamada Reza de Ibejis e após as crianças sentam-se ao chão, em torno à mesa, servindo-se à vontade de tudo o que ali se encontra. Esta mesa é comandada pelos Oriás Oxum e Xangô. Ao final, levantam-se ritualisticamente os alimentos e a toalha iniciando-se a obrigação final para os Orixás.

Finalizando, queremos nos referir a um Centro que trabalha no ritual Nagô e que, a nosso ver, realiza um culto diferente de todos os demais existentes no Rio Grande do Sul. Isto é, ele e outro localizado em Bagé, cidade fronteiriça do estado, e que dele se originou. Trata-se de Centro Espírita de Umbanda Nova Era, dirigido pelo irmáo Jader do Xangô e tendo como auxiliar direto o irmáo Mário do Ogum.

Sobre ser um templo dotado de todos os requisitos exigidos pelas nossas Religiôes, eis que se dedica às duas linhas: Umbanda e Nação. É uma sociedade perfeitamente organizada no sentido de manter a sua subsistência sem a necessidade de cobrança aos frequentadores. Tudo ali é gratuito e apenas se pede, aos que tenham condiçôes, aquisição do material necessário à confecção dos trabalhos solicitados pelas entidades.

Se a Umbanda é uma linha mais aberta, perto de 200 médiuns, o seu Culto Africano é fechado e nele ingressam poucos e escolhidos pelos Orixás (são cerca de 70). Aos médiuns de Umbanda é facultado assistirem aos trabalhos de Nação, mas a sua admissão só é levada à apreciação dos Orixás depois que o Babalorixá esteja convicto de que o elemento está entrando porque deseja realmente participar do Culto e não movido por

${ }^{15}$ É uma das formas de denominar o processo ritual da feitura, quando se sacrifica um animal de pelo, como já referiu o autor. De tempo em tempo (dependendo da Casa e da Naçáo) essa "obrigação" deve ser renovada, mantendo uma constante de rituais.

Debates do NeR, Porto Alegre, ano i9, N. 35, P. 2 I-38, Jan./Jul. 20 i 9 
um entusiasmo passageiro. Isto faz com que o grupo integrante da Nação seja coeso e sofra raríssimas defecçóes.

Tal orientação foi-lhe transmitida por sua Mãe-de-Santo, já desencarnada, Lúcia de Ibejis, filha de africanos legítimos e que possuía uma pequena casa em Pelotas, onde Jader se iniciou, sendo hoje o último remanescente do grupo. É de se ressaltar o grande respeito que dedica à sua Mãe-deSanto e a preocupação em resguardar, intactos, todos os ensinamentos que lhe foram transmitidos. Ressaltamos tal fato pois hoje, com o ingresso de elementos de cultura superior dentro da Religião, nota-se um descaso para os fundamentos que lhes são transmitidos por Pais e Mães, algumas vezes analfabetos ou semi-analfabetos.

A primeira impressão que nos causa a sua Casa é a aparente suntuosidade do prédio e esta é quebrada ao ingressarmos, já que impera em seu interior a simplicidade, ainda que revestida de um bom gosto oriundo do Dirigente, que é artista plástico. Logo após contata-se a praticidade da distribuição dos aposentos dentro do imóvel com a parte superior destinada à guara dos otás $^{16}$, aos vestiários e uma sala de reuniôes. A parte inferior com a Secretaria à entrada, o saláo propriamente, com um local para a assistência de, em média, 100 lugares sentados, as salas de consultas para os Pretos-Velhos e uma cozinha. Ao fundo, um pátio lajeado e com gaiolas individuais para a guarda de aves e um cercado para os animais de quatro pés e uma longa mesa que serve, inclusive, para a coureada e limpeza dos mesmos.

As obrigações de Nação se distinguem das demais Casas pelo fato de que esta, muito raramente, oferece um toque para os Orixás. Geralmente fazem apenas o chamado Serão, onde são sacrificadas as oferendas e durante estas chegam os Orixás na devida ordem. É de se notar que esta Obrigação é efetuada sem a presença da assistência, participando apenas convidados especiais.

Longe de acompanhar o hábito da permanência dos filhos dentro do saláo, a casa promove uma entrada ritualística. Em fila indiana e ao som do adjá tocado pelo dirigente maior. Os médiuns, à medida que entram,

$\overline{16} \mathrm{Ou}$ Okutás, são as pedras em que são assentados os orixás. 
batem cabeça, tomam a bênção do Pai e se colocam já na Roda da posição ritualística. O Ecó é despachado ao início pelo Ogã de Peji desincorporado, eis que não possuindo a Casa, de momento, filhos de Bará na corrente, coube a tarefa a esse irmão pela sua qualidade de filho de Ogum.

Inicia-se o toque com as rezas de bará e a seguir as dos Orixás masculinos. Findos estes, entram as invocaçōes para os femininos, encerrando-se com as de Oxalá. E aqui vai outra discrepância com referência aos demais rituais: na medida em que se puxam as rezas váo chegando os Orixás invocados que dançam até o seu final e, ainda que náo sejam obrigados quase sempre se retiram ao final das mesmas. Assim sendo, é difícil vermos Orixás de mais de uma linha incorporados durante a Obrigação. Outro fato a se destacar é o de que cada Orixá que se dirige ao peji ${ }^{17}$ para a deincorporação é saudado pelos elementos da corrente e da assistência com uma salva de palmas em agradecimento à sua presença junto a nós.

Findos os trabalhos, os médiuns formam uma linha ao centro do salão e, aí, cantando o ponto de agradecimento aos Orixás, vão recuando até a porta dos fundos, onde se curvam, agradecendo a presença dos visitantes que retribuem a gentileza com uma salva de palmas. Este cerimonial talvez tenha sido o único introduzido pelo Jader para, segundo me disse, quebrar um pouco do formalismo que imperou durante o Seráo.

É de se notar que os Toques são considerados como uma festa oferecida aos Orixás e, portanto, são realizados apenas em ocasiōes especiais com a presença da corrente uniformizada e com apenas algumas rezas dos Orixás (três no máximo). Findas estas coloca-se uma mesa no chão e convida-se a assistência, agora em maior número, pois é uma cerimônia aberta, para participar do ágape dentro da ritualística, ou seja, sem o uso de talheres.

Cabe ainda um reparo sobre a matança que separa a ritualística em duas partes: os animais sacrificados nas obrigaçôes dos iniciados ou dos que se estão aprontando e os que são oferecidos pelos já preparados para os seus Orixás. No primeiro caso, a faca é empunhada pelo Babalorixá e no segundo

${ }^{17}$ Quarto de santo. 
cada filho sacrifica a sua própria oferenda. Ressaltamos, ainda, que esta foi a única Casa em que vimos sacrificar animais não suspensos pelas patas, mas, isto sim, deitados sobre o solo onde permanecem até o resfriamento total do corpo. Os que tiveram a oportunidade de ler o livro Magia y Sacrificio em la Historia de las Religiones, de H. Hubert y M. Mauss, traduzido para o castelhano e editado pela Lautaro de Buenos Aires, poderão perfeitamente aquilatar o valor que para nós teve assistirmos uma cerimônia como essa. Caberia, a nosso ver, um estudo mais aprofundado desse Ritual e rogamos aos Pais nos possibilitar fazê-lo ainda que o tempo se nos afigure curto para tarefa de tal monta.

Isto era o que tínhamos a oferecer aos irmãos escusando-nos por qualquer falha decorrente de nossas limitaçóes e, principalmente, da dificuldade de sintetizarmos um assunto de tanta vastidão no exíguo tempo que uma convenção dá aos seus palestrantes.

\section{ORIKI PARA OLORUM}

Olorum maieme (piedade)!

O Senhor, Meu Pai, é o Divino Criador,

Aquele de quem nascemos e para $\mathrm{O}$ qual retornaremos.

Somente em ocasiōes especiais Vos invocamos.

Sabemos que a direção do mundo

Vós a entregastes aos orixás

Representações das Vossas Forças Divinas.

O Orum (Céu) e o Aye (Terra) foram por eles criados em Vosso Nome.

Eles estão dispostos como uma gamela partida ao meio

E o que se encontra no Orum deveria refletir-se no Aye

E tal não sucede porque quando concedeste ao homem o livre arbítrio

O equilíbrio foi quebrado pelo seu mau uso e,

Assim, os males iniciaram, as dores se espalharam, 
Os períodos de paz começaram a rarear

$\mathrm{E}$ os homens entregaram-se às lutas fraticidas, inclusive em Teu Nome, Esquecidos de que és paz, amor e luz.

Volta agora a situação a agravar-se em uma luta de final imprevisível.

Veremos novamente inocentes serem imolados pela sede de poder

E pela intransigência religiosa.

A cobiça e o fanatismo iniciam sua caminhada sangreta

E a dor começa a ferir os teus filhos.

Neste caso nada nos resta se não recorremos a Ti

Suprema Divindade e Pai de todos nós,

Para que com os teus imensos poderes

Ilumines a mente de nossos dirigentes

Demovendo-os de seus propósitos egoísticos.

Que lhes faças ver o temporal de ódio e de dores que desencadearâo

Simplesmente por uma sede de poder e de vaidades inúteis.

Ouve, Olorum, a súplica sentida de teus filhos.

A quem nada mais resta senão buscar o amparo em $\mathrm{Ti}$.

Alafiá (Misericórdia) para esta humanidade sofredora.

Recebido em: 27/10/2018

Aprovado em: 27/10/2018 